\title{
Fortalecer la territorialidad en las comunidades
}

\section{Strengthening Territoriality in Communities}

\author{
María Gabriela Hernández López \\ Universidad Nacional \\ Heredia, Costa Rica \\ gabiher@gmail.com
}

Recibido: 26/02/2018 Aceptado: 06/06/2018

Resumen. Este artículo reflexiona sobre los territorios como construcciones sociales producto de las relaciones de poder entre grupos en constante tensión, las cuales configuran los espacios y las temporalidades dando lugar a nuevas simbologías y geografías. Se parte de que la Universidad Nacional ha construido, desde su propia territorialidad (campus), una lógica de regionalización, como proceso histórico, social y político, para administrar los recursos y ejercer su autonomía. Este imaginario histórico-social ha servido de marco a las acciones de extensión, mismo que ha respondido a una lógica del modelo "nacional" de "desarrollo", el cual, al día de hoy, se ha visto influenciado por otros procesos recurrentes, como la globalización neoliberal, que ha incrementado la desigualdades territoriales ya existentes. Esto motiva a la autora a proponer algunas políticas que promuevan la equidad territorial en una relación recíproca entre universidad y comunidades, que responda a procesos planificados y continuos desde la extensión universitaria. 
Revista Universidad en Diálogo • Vol. 8, N. ํㅡㄹ Julio-Diciembre, 2018, pp. 51-69

ISSN 2215-2849 • EISSN: 2215-4752

DOI: http://dx.doi.org/10.15359/udre.8-2.4

Palabras claves: comunidades, descentralización, desconcentración, desarrollo local, democracia, regionalización, territorialidad, universidades públicas.

Abstract. This article reflects on the territories as social constructions that are a product of the power relations between groups in constant tension; these constructions configure spaces and temporalities giving place to new symbols and geographies. It is assumed that the National University of Costa Rica has constructed, from its territoriality (the campus), a logic of regionalization as a historical, social, and political process to manage the resources and exercise its autonomy. This historical and social imaginary has been used as a framework for university extension actions; the framework has also responded to a logic of the national model of development that has been influenced by other processes. Currently, the neoliberal globalization is one of these processes that has increased the territorial inequalities already existing. This situation motivates the author to propose some policies that promote the territorial equality in a reciprocal relationship between the university and communities to respond to planned and continuous processes from the university extension activities.

Keywords: communities, democracy, decentralization, deconcentration, local development, regionalization, territoriality, public universities.

\section{Justificación}

La interrogante principal sobre la que se apoya esta investigación es: ¿Se pueden construir procesos de bienestar socioeconómico glocales,${ }^{1}$ en territorios con construcciones sociales que son producto de las relaciones de poder entre grupos en constante tensión y configuración física y temporal? Una cuestión que se justifica en un marco donde los procesos globalizadores entran en tensión con los procesos de planificación del desarrollo nacional y la configuración propia de los territorios a nivel local (comunal y municipal).

Para poder crear dispositivos para la acción en la búsqueda del bienestar comunal resulta fundamental analizar la dimensión sociopolítica en relación con el tiempo y el espacio, en niveles macro, meso y micro, que permitan caracterizar diferentes relaciones, escalas, redes, localidades, personas

\footnotetext{
“...se refiere a lo global y lo local como una relación donde ambos se construyen mutuamente (aunque, como se ha visto, de forma asimétrica), el territorio es la concreción, con arraigo, de esa íntima relación y construcción" (Santos, 2009, p. 30).
} 
involucradas y formas de ser que son expresiones de diferentes formas de poder. En esta construcción epistemológica que propongo están las voces de algunos autores escogidos para este diálogo, que sirven para discutir variados tópicos relacionados con las dinámicas espaciales-temporales, y algunos de los diversos procesos sociopolíticos construidos a partir de estos.

A nivel macro, autores como Robinson (2015) cuestionan que el discurso dominante sobre la desigualdad global sea territorial. Por el contrario, el autor indica que la polarización global es menos territorial que social, y refuerza esta afirmación señalando que el "sur global" se dispersa cada vez más por el mundo, al igual que el "norte global", definiendo jerarquías sociales y desigualdades de tipo mundial, no de tipo nacional. Dicha expresión globalizante define un patrón geográfico emergente y da como resultado el aumento de la heterogeneidad de los mercados y de las reservas de trabajo en cada localidad, desde mano de obra muy calificada a obreros con bajo nivel educativo, combinando centro-periferia en una misma localidad.

Siguiendo el planteamiento de Robinson, el desafío para las ciencias sociales en todos los niveles o escalas territoriales es pensar en términos de "grupos de población desarrollados, subdesarrollados e intermedios que ocupan lugares inestables y contradictorios en un entorno transnacional" (2015, p. 65), por lo demás llenos de avatares y que, en palabras del mismo autor, responden a una lógica de fin del neoliberalismo, dentro de la lógica del sistema-mundo. Sería pensar en una América Latina y, de forma más específica, en una Centroamérica con "crisis endémica" de estancamiento económico y desigualdad globalmente creciente que, al igual que en el resto del mundo, deja ver la inestabilidad social, la tensión política y el conflicto militar. Si el Estado de bienestar fue la apuesta a un enfoque keynesiano, ¿qué viene después de la crisis de un bloque transnacional que reemplaza al bloque desarrollista?, ¿qué ocurrirá cuando los mecanismos de especulación financiera o el crédito ya no puedan sostener la acumulación y las ganancias no se puedan lograr en una economía capitalista globalizada? ¿qué ocurrirá con los Estados deslegitimados y el uso de la industria bélica para controlar el orden global actual? Ese es el desafío, construir una tesis esperanzadora, que promueva la recuperación de una moral universal, de una economía y ecología respetuosa del enfoque de equidad y derechos humanos, de un postdesarrollo urgente que contrarreste los destructivos procesos locales, nacionales y regionales, producto de este "apartheid social globalizante", según lo define Robinson (2015). 
ReVista Universidad en Diálogo • Vol. 8, N. ${ }^{\circ}$ 2, Julio-Diciembre, 2018, pp. 51-69

ISSN 2215-2849 • EISSN: 2215-4752

DOI: http://dx.doi.org/10.15359/udre.8-2.4

El territorio donde habitamos es pensado, dentro del imaginario social de la administración pública nacional, como un modelo de planificación racional, definido mediante la noción de regionalización, dentro de lo que Rafael Miranda (2010, p. 94) señala, a partir del planteamiento de Castoriadis (1975, p. 401), como el factor de cohesión de la sociedad y en cuya crisis, para efectos de esta ponencia, hay que incluir el denominado Estado de bienestar o desarrollista, que enfrenta a procesos intensos de cambio a partir de la globalización mundial. Por otro lado, los procesos glocales (a nivel comunal y municipal) de los territorios responden al concepto de $t e-$ rritorialidad, ${ }^{2}$ desde donde conviven diferentes tipos de saberes y culturas.

Las entidades estatales pueden cumplir diferentes roles desde diversas perspectivas en la promoción del bienestar regional o glocal; de forma específica, interesa analizar el quehacer universitario de la Universidad Nacional de Costa Rica, mediante su propuesta basada en el enfoque filosófico del diálogo de saberes, definido en el Estatuto Orgánico como "el conocimiento procedente de culturas y prácticas históricas seculares [que] contribuye, junto con las fuentes y los procesos propios de creación de conocimiento, al desarrollo del quehacer académico universitario" (Universidad Nacional, 2015, p. 20).

Santiago Castro (2007) advierte sobre el diálogo de saberes que de nada sirve incorporar la transdisciplinariedad y el pensamiento complejo, si ello no contribuye a permitir un intercambio cognitivo entre la ciencia occidental y formas postoccidentales de producción de conocimientos.

Por otro lado, De Sousa ${ }^{3}$ refuerza esta idea con el siguiente planteamiento: "Eso, a mi juicio, es otra epistemología, otro conocimiento. Por eso afirmo que no hay justicia social global sin justicia cognitiva global, ni justicia

2 Citando a Tirso Maldonado, comunicación personal en enero de 2017 durante el taller de Planificación Estratégica 2017-2022: "La regionalización es un proceso de arriba-hacia abajo", mientras que la territorialidad es un proceso de "abajo-hacia arriba". Asimismo, Mario Samper señala lo siguiente: "Un territorio es un espacio socio-geográfico •construido cultural, social e históricamente, •donde interactúan los seres humanos entre sí y con la naturaleza" (Samper y Torrens, 2014).

3 Para Boaventura de Sousa,( 2007) la modernidad se transformó en capitalismo que marcó el conocimiento de la regulación y convirtió la emancipación (o conocimiento emancipador) en ignorancia y el colonialismo en orden. El autor señala que la ecología de saberes no significa desconocer la ciencia, de ahí la importancia de que los conocimientos se articulen unos con otros, no que se eliminen unos a otros, lo que él denomina como epistemicidio. 
social global sin justicia cognitiva y reconocimiento" (2007, p. 110).

En procesos de reflexión institucional, donde la universidad autónoma se encuentra frente a procesos de cambio importantes que ponen a prueba al proyecto nacional desde hace treinta años, la reflexión de De Sousa se vuelve pertinente.

Para los países periféricos y semiperiféricos no hay calificación sin que la resistencia a la globalización neoliberal se traduzca en estrategias de globalización alternativa... La universidad pública sabe que sin proyecto nacional sólo hay contextos globales y estos son demasiado poderosos para que la crítica universitaria de los contextos no acarree la propia descontextualización de la universidad. El "exceso de lucidez" de la universidad le permite denunciar que "el emperador va desnudo" y es por eso que la reforma de la universidad será siempre diferente de todas las demás $(2007$, p. 55).

Como parte de la institucionalidad universitaria, de manera particular, interesa analizar la extensión como el medio para llegar a las comunidades excluidas del bienestar socioeconómico. La extensión forma parte de la acción sustantiva de esta universidad, la cual se ve afectada de manera particular por estos procesos de cambio que representan una nueva cultura política y administrativa, donde fenómenos globalizantes como la sociedad del conocimiento (que demanda nuevos roles en la generación del conocimiento más allá de los campus y su tradicional función académica), así como los tratados internacionales para la venta de servicios ${ }^{4}$ que promueven la privatización de la educación superior y la demanda de organismos internacionales que definen el modelo de desarrollo mundial, incluyendo la educación superior, ${ }^{5}$ marcan nuevas pautas al accionar de la Universidad Nacional (UNA) de Costa Rica.

Tales como el Trade in Services Agreement (TISA) o Acuerdo sobre el Comercio de Servicios (ACS). La historia del TISA comenzó en el año 2012 cuando dieciséis países decidieron constituirse como grupo promotor, bajo la llamativa denominación de Really Good Friends of Services (RGF), para impulsar la adopción de un nuevo tratado multilateral de servicios. Hasta noviembre de 2016 se han mantenido veintiuna rondas de negociaciones en Ginebra. No hay un plazo establecido para poner fin a las negociaciones. Para ahondar en el tema véase http://ec.europa.eu/trade/ policy/in-focus/tisa/index_es.htm

Se puede citar a la Organización para la Cooperación y el Desarrollo Económico, OCDE (con sus criterios de desarrollo y con sus metodologías de planificación), el Banco Interamericano de Desarrollo o el Banco Mundial (mediante los convenios con el Estado y las universidades públicas). 
ReVista Universidad en DiÁlogo • Vol. 8, N. ํㄹ 2, Julio-Diciembre, 2018, pp. 51-69

ISSN 2215-2849 • EISSN: 2215-4752

DOI: http://dx.doi.org/10.15359/udre.8-2.4

Es importante hacer referencia a la presencia de la extensión en la UNA, la cual se ha implementado desde diferentes instancias con presencia regional, tales como las sedes, subsedes, intersedes, unidades académicas, institutos, direcciones o vicerrectorías. ${ }^{6}$ El compromiso social de la UNA con las comunidades ha sido un norte para la institución, mismo que debe ser revisado críticamente en su accionar glocal y regional.

\section{Metodología}

Este artículo está basado en la referencia explicativa a nivel cualitativo de la actual territorialidad costarricense, así como los procesos de regionalización, desde la perspectiva de diferentes academicistas y enfoques, de acuerdo con la realidad y el contexto histórico actual, según fuentes secundarias. Es un primer acercamiento a varias perspectivas referidas, para el abordaje de

la territorialidad y la praxis extensionista universitaria de la UNA.

\section{Políticas y dispositivos nacionales para la regionalización}

Para efectos de este análisis se debe aclarar que, a pesar de que la regionalización ha sido acompañada por disciplinas como la geografía y la economía, se parte de que es una expresión fundamentalmente sociopolítica, como también lo es para cualquier enfoque territorial de planificación y desarrollo. Santos (2009, p. 147) sustenta esta afirmación al advertir que el espacio es una "instancia", tanto social como económica y culturalideológica, donde todos y cada uno se contienen uno en el otro, donde los "objetos geográficos están distribuidos sobre un territorio" como paisaje, y a cuyos objetos dan vida "los procesos sociales representativos de una sociedad en un momento dado" y a través de formas específicas.

Existen variantes en la regionalización definida desde la institucionalidad costarricense. Hernández (2017) hace referencia a la distribución espacial nacional, misma que ha sido creada de manera precisa según

\footnotetext{
6 "Programas, Proyectos y Actividades Académicas de la extensión de la UNA: La labor de extensión universitaria se organiza en Proyectos Académicos (PPAA) y es ejecutada en las 41 unidades académicas (escuelas, institutos y centros) de ocho facultades, un campus central, tres sedes regionales y una intersede. De esta manera, la extensión de la UNA es 'un mecanismo efectivo de transferencia de los beneficios de la educación, de la investigación y de la cultura a los diversos sectores sociales"” (Monge, Lescano y Méndez, citados por Zlaveta, 2016, p. 13).
} 
normativa y dispositivos de intervención, dentro de la lógica de un Estado desarrollista y de democracia formal, que responde a una lógica racional del conocimiento. El Estado costarricense crea una de las formas más significativas de esta regionalización del territorio nacional, mediante el Decreto Ejecutivo No 7944 del 26 de enero de 1978, que comprende la subdivisión político-económica de Costa Rica. En la actualidad están vigentes seis regiones: Región Central (la de mayor densidad poblacional que se ramifica en Central Norte, Central Occidental, Central Oriental y Central Sur), la Región Chorotega, la Región Pacífico Central, la Región Brunca, la Región Huetar Atlántica y la Región Huetar Norte). A nivel institucional, la organización básica del Sistema de Regionalización se concentra en el Ministerio de Planificación Nacional y Política Económica (Mideplan) como ente superior para la planificación en coordinación con las respectivas regiones mediante los Consejos Regionales de Desarrollo y los Comités Sectoriales Regionales.

Otro ejemplo que compete de manera directa al tema de este artículo, es el caso de las universidades públicas y privadas, ya que según el Sexto Informe del Estado de la Educación (2017) persisten importantes diferencias en la oferta educativa, ${ }^{7}$ como respuesta a la estructura de regionalización universitaria y de cada zona particular en el país. Así en el caso de las universidades públicas, el Informe nos da cuenta de lo siguiente:

Las sedes de las universidades estatales se concentran sobre todo en las regiones Chorotega y Huetar Atlántica, mientras que la mayor parte de las privadas se ubica en la Brunca y la Huetar Atlántica... La oferta académica en las regiones periféricas no solo es limitada en cantidad de programas, sino que presenta una concentración por área del conocimiento incluso superior al promedio nación de la oferta académica en las áreas de Educación, Ciencias Sociales y Ciencias Económicas (2017, p. 248).

Por otro lado, existe otra forma de regionalización, según señala Barrantes (1997), refiriéndose al Ministerio de Educación Pública:

El informe plantea que las universidades públicas, como respuesta de los programas de becas instituidos, cubren un poco más del 50\% de la población estudiantil y superan el $80 \%$ en las sedes regionales: "Tienen una importante penetración en los quintiles de menores ingresos" (Sexto Informe Estado de la Nación). Estos grupos representan a los más vulnerables (extrema pobreza y población indígena). 
ReVista Universidad en Diálogo • Vol. 8, N. ${ }^{\circ}$ 2, Julio-Diciembre, 2018, pp. 51-69

ISSN 2215-2849 • EISSN: 2215-4752

DOI: http://dx.doi.org/10.15359/udre.8-2.4

...representa un modelo centralizado del sistema educativo costarricense, sobre el cual el país decidió - a partir de la década de los setenta- atribuir algunas funciones a los organismos educativos regionales para la desconcentración, pero manteniendo una relación de dependencia jerárquica con la Administración Central. Estos criterios determinan la división del país en cinco regiones: Chorotega, la Brunca, la Central y la Huetar Norte y Huetar Atlántica. Estas regiones a su vez se subdividen en 22 subregiones (p. 1).

Este artículo parte de una premisa fundamental y es que en cualquier esquema de división territorial nuestro país requiere un diseño más equilibrado para la definición de políticas y el ejercicio democrático de la Administración pública en general. Un modelo centralizado ya ha demostrado ser una importante causa de desigualdad estructural y territorial. Se parte de que un diseño descentralizado de la política pública (nacional y regional) alienta el impulso de la democratización en la toma de decisiones de políticas públicas y su puesta en práctica, de forma equitativa e incluyente. El fundamento de esta afirmación se engloba en sí en la necesidad de fortalecer las iniciativas para impulsar la gestión de recursos desde lo local en un mundo global, en el marco de escenarios desde la descentralización, como una respuesta equilibradora de esas inequidades territoriales.

Según Arias y Sánchez (2013):

Las desigualdades socioeconómicas menoscaban el capital social y las relaciones de solidaridad y tolerancia dentro de una sociedad. Esta situación a su vez condiciona la cohesión social y la participación en el proceso de toma de decisiones. Las sociedades más desiguales son aquellas donde estas condiciones prevalecen, no es casual que sean estas sociedades las que menos invierten en desarrollo humano y en redes de apoyo social (p. 4).

Los mismos autores señalan otras deficiencias presentadas por estas desigualdades estructurales a nivel socioeconómico, que limitan la gobernabilidad democrática,

a) Los altos niveles de concentración de la propiedad; b) Los problemas para acceder a la educación y la salud; c) Las dificultades para acceder al crédito y a empleos en el sector formal de la economía; d) La feminización del sector informal y de la pobreza y la exclusión de las minorías étnicas (p. 4). 
Después de más de treinta años de regionalización, mediante la creación de territorios imaginarios que pretenden, al día de hoy, "facilitar" la administración de los recursos del Estado y la asignación de los mismos para promover el desarrollo nacional, encontramos que el significado de tiempo y el de espacio varían según la entidad social afectada. ${ }^{8}$

El testimonio del dirigente indígena González representa este significado para una parte de la población: ${ }^{9}$

La sociedad no indígena ha construido el sistema de tal forma, que se interprete erróneamente si los Pueblos Originarios son propiedad de alguien, o en este caso, de algo. El sistema de occidente debe superar la frase trillada "nuestros indígenas" en sus discursos, pues al asimilar la propiedad de algo, el paternalismo estatal se acrecentará mucho más. Los Pueblos no son propiedad de un Estado, de un país, son conglomerados culturalmente identificados que viven dentro de ellos, con rasgos diferenciados de la sociedad numerosamente "predominante". Resumidamente, los grupos humanos no son ni deben ser activos de algo o alguien, yo al menos no soy "suyo", nunca lo he sido. Superemos términos altamente discriminatorios, busquemos la manera de que el ser humano deje de ser propiedad de otro (González, 2017, s. p.).

Tratando de superar la inequidad regional, la Administración gubernamental Solís Rivera ha creado algunas iniciativas para promover la igualdad desde una perspectiva territorial y democrática: existe, por ejemplo, la Consulta Nacional Indígena para la definición de lineamientos estratégicos en y con los territorios indígenas, el fortalecimiento del rol del Instituto Nacional para el Desarrollo Rural (INDER) por medio de Fondos para el Desarrollo Rural, que contribuyan a la implementación de políticas y pactos sociales e institucionales que faciliten la equidad socioeconómica y minimicen las malas prácticas en la

$8 \quad$ Significado de espacio y de tiempo en los territorios: "En cada sociedad concreta dichos espacio y tiempo propios de un mismo tipo de patrones de interacción social no son idénticos" (Sotolongo y Delgado, p. 117).

$9 \quad$ Según el artículo 13 del Convenio 169 de la Organización Internacional del Trabajo, ratificado por el gobierno de Costa Rica el 02 de abril de 1993, el territorio indígena incluye "la totalidad del hábitat de las regiones que los pueblos interesados ocupan o utilizan de alguna otra manera". En teoría, la ley las dota de autogobierno y autonomía política y judicial en donde las autoridades nacionales y municipales no pueden intervenir, sin embargo, en la práctica, esta autonomía no siempre se cumple. Actualmente existen veinticuatro territorios indígenas de ocho etnias formalmente reconocidas por el Estado: Teribe, Guatuso, Bribrí, Huetar, Chorotega, Ngöbe y Cabécar. 
Revista Universidad en Diálogo • Vol. 8, N. 2, Julio-Diciembre, 2018, pp. 51-69

ISSN 2215-2849 • EISSN: 2215-4752

DOI: http://dx.doi.org/10.15359/udre.8-2.4

administración pública y privada, que fomentan círculos viciosos, fortalecidos desde esta estructura desigual. Sin embargo, las diferencias estructurales requieren de otras acciones inclusivas en el largo plazo.

La ministra de Mideplan, Olga Marta Sánchez Oviedo (Eurosocial, 2017), hace referencia al proceso de regionalización que pretende revertir esta inequidad territorial:

El enfoque regional no sólo implica compensar a las regiones menos desarrolladas por sus desventajas, sino también mejorar el crecimiento y la competitividad de cada una de ellas, estableciendo políticas nacionales que contribuyan a disminuir las disparidades para el desarrollo integral del país, desde principios de equidad, focalización, en pro de aumentar los niveles de bienestar y mejoramiento de las condiciones de vida de las personas que habitan en cada territorio (p. 2).

Este déficit estructural sobre la inequidad territorial afecta este imaginario social, pues las percepciones variarán según el contexto histórico, por ejemplo, el Informe del Programa Estado de la Nación de 2001 sobre estabilidad democrática señala que "con todo y la alta insatisfacción ciudadana registrada por las encuestas de opinión, no hay síntomas de ingobernabilidad como en otros países de América Latina, y persiste un apoyo mayoritario de la población hacia la democracia" (PEN, 2000, p. 247).

Sin embargo, dieciséis años después, el XXII Informe del PEN (2016) nos indica de forma contraria que "en la actualidad las personas están claramente insatisfechas con el rumbo del país, las oportunidades para conseguir un buen empleo y la situación comparada con la época de sus padres". ${ }^{10}$ (p. 295).

Esto presenta el doble sentido que la democracia puede significar para los y las costarricenses, tanto en los cuestionamientos mismos sobre su significado y la delegación del poder en otras personas, así como la calidad de vida a partir de la administración pública de los recursos disponibles.

10 Esta misma fuente nos indica que en la escala de insatisfacción de 1 a 10 ( 0 es nada descontento y 10 es muy descontento), el porcentaje promedio de insatisfacción es de $7.5 \%$. El descontento no se concentra en grupos en específico, sino que está relativamente repartido a lo largo y ancho de la sociedad. 


\section{Dialogando sobre territorios}

Advierte Carmen (2004, p. 104) que es difícil encontrar una alternativa para promover "las bondades de la democracia" de manera inclusiva para los pueblos dominados, cuando muchas estrategias de desarrollo local o comunal han fracasado, al ser "absorbidas por las élites aldeanas tradicionales". De igual manera, el mismo autor hace un llamado para cuestionar críticamente conceptos como el de comunidad, al denominarlo "un concepto de una elasticidad casi infinita, inmediatamente adoptado por todo el espectro de las orientaciones políticas". También nos refiere a una propuesta que él denomina como el proceso liberador, mediante un desarrollo humanizante (a nivel organizativo), independencia económica o autoabastecimiento (a nivel técnico) y autodesarrollo (a nivel espiritual).

En el caso de Costa Rica, tal como lo señala León (2015), el desarrollo geográfico desigual, al igual que lo plantea Wallerstein (1999), es una consecuencia del sistema capitalista. Este busca la "producción en escalas y por tanto requiere anclarse en algún lado" (p. 13). Por lo tanto, deriva de este sistema de producción un Estado territorial con tensiones y contradicciones de escala. Así, el capitalismo en Costa Rica se ha consolidado como una producción de regionalidades, definidas por León como "procesos moleculares de acumulación" (p. 19) que dan paso al desequilibrio de las relaciones de poder entre instituciones políticas, fuerzas sociales y capitales en espacios y territorios específicos. Siguiendo con el pensamiento de León, es importante para esta construcción epistemológica la definición dada por Fürst (2013) sobre el concepto de espacio: "Un proceso socialmente construido e impugnado en sus ámbitos local-rural, local-urbano, metropolitano, regional, nacional y global, que se transforma dialécticamente (ambivalente y no determinista) con la globalización que equivale a una acumulación por desposesión" (p. 175).

Otros autores como Boaventura de Sousa (2007), dentro de la corriente de pensamiento crítico decolonial, establecen que la herencia colonial para continentes como el nuestro son el reflejo de una historia que define la modernidad occidental, dentro de la cual no se construye más que el capitalismo, el cual se sustenta en un conocimiento de regulación que pasó a dominar totalmente y, por tanto, transformó, absorbió el conocimiento de emancipación. Siguiendo este análisis, señala el mismo autor: 
El conocimiento de emancipación, pasó a ser ignorancia, la solidaridad pasó a ser caos solidario entre ciudadanos, el peligro de la solidaridad entre ciudadanos; la emancipación pasó de ignorancia en el colonialismo a ser orden, y lo es de una buena manera (p. 3).

De igual forma, en la obra Tecnología para la liberación (Riedjik, citado por Carmen, 2004, p. 114) se propone el abordaje multidimensional del desarrollo local mediante dispositivos que responden a tecnologías apropiadas que, en palabras de De Sousa, se refiere a la diferencia entre el saber racional (o regulador) y el saber emancipatorio. Según el aporte de estos autores, las dimensiones que se ponen en juego en ambos enfoques contrastados son:

\section{a) Dimensión social del territorio:}

Enfoque regulador: Democracia formal y representativa, centralización.

Enfoque emancipatorio: Democracia ciudadana participativa, descentralización, actores comunitarios como sujetos y protagonistas de su desarrollo.

\section{b) Dimensión económica del territorio:}

Enfoque regulador: Sobreabastecimiento, técnicas duras (tecnología industrial para mercados masivos de consumo), consumo, desperdicio, compleja.

Enfoque emancipatorio: Autoabastecimiento, técnicas suaves (tecnologías apropiadas social y productivamente, según necesidades locales), reciclaje, frugal, simple.

\section{c) Dimensión política del territorio:}

Entendida, según Sosa (2012), como la concreción del ejercicio histórico del poder; el Estado como configurador del territorio, el territorio configurado desde poderes globales; poderes sobre el territorio; el lugar de las políticas territoriales.

Enfoque regulador: Subordinación, burocracia, centralización, grande, uniformidad.

Enfoque emancipatorio: Automanejo/administración, democracia participativa y ciudadana, descentralización, pequeño, pluriformidad. 


\section{d) Dimensión cultural del territorio:}

Territorio como espacio de inscripción de cultura; territorialidad cultural; territorio e identidad.

Enfoque regulador: Alienación, dominación, desigualdad.

Enfoque emancipatorio: Autodesarrollo, emancipación, participación, interculturalidad en los procesos colectivos de construcción del desarrollo local.

Para que las universidades públicas fortalezcan la territorialidad, desde la perspectiva del pensamiento emancipador, De Sousa (2007) plantea la necesidad de una reforma universitaria de la extensión, la investigación y de la docencia desde lo glocal, como una respuesta contrahegemónica para enfrentar además las tres crisis actuales de las universidades públicas: la hegemónica, la de legitimidad y la institucional. ${ }^{11}$

\section{Conclusiones}

Finalmente, como conclusión de este diálogo entre los citados autores, coincido en que el sistema capitalista ha construido un conocimiento-pensamiento que no contribuye a la igualdad espacial, para su reproducción y acumulación.

Algunos sectores sociales de forma contrahegemónica buscan y crean procesos emancipatorios a esta tendencia, de forma dinámica, de manera que les permita el acceso y control sobre recursos y servicios espaciales de forma equitativa.

Mientras la normativa y los dispositivos para la regionalización sigan siendo definidos desde espacios centralizados por las élites sociopolíticas, fundamentados en el conocimiento racional y excluyendo el diálogo de saberes, a pesar de

11 Según De Sousa, en relación con la hegemonía, "la universidad debe entender que la producción de conocimiento epistemológica y socialmente privilegiada y la formación de élites dejaron de tener el poder, por sí solos, de asegurar la legitimidad de la universidad a partir del momento en que ella perdió la hegemonía, inclusive en el desempeño de estas funciones, y tuvo que pasar a desempeñarse en un contexto competitivo. La lucha por la legitimidad permite ampliar el potencial de estas funciones, complementándolas con otras donde el vínculo social sea más transparente. Para que eso ocurra, la universidad debe dotarse de condiciones adecuadas tanto financieras como institucionales... Una vez creadas las condiciones, la universidad debe ser motivada para asumir formas más densas de responsabilidad social, pero no debe ser solamente entendida de manera funcionalista en este sentido. La responsabilidad social de la universidad debe ser asumida por la universidad aceptando ser permeable a las demandas sociales, especialmente aquellas originadas en grupos sociales que no tienen el poder para imponerlas" (2007, p. 69). 
Revista Universidad en DiÁlogo • Vol. 8, N. ², Julio-Diciembre, 2018, pp. 51-69

ISSN 2215-2849 • EISSN: 2215-4752

DOI: http://dx.doi.org/10.15359/udre.8-2.4

la descentralización y desconcentración pretendida por muchas personas, esta no dinamizará procesos de desarrollo endógeno ni la construcción de espacios con equidad social que posibiliten el fortalecimiento de la territorialidad.

Lo importante es llegar al reconocimiento de que el manejo del espaciotiempo es una construcción sociopolítica que puede ser recreada desde estas perspectivas, con enfoques diversos para la construcción de dispositivos, normativa o reglas que las rigen, de forma dinámica y en constante proceso de cambio, desde donde, como afirma Inmanuelle Wallerstein (1999), conviven la coyuntura con la estructura.

La extensión universitaria seguirá siendo la respuesta que las universidades públicas den a los sujetos excluidos del sistema, lo que exige trabajar conjuntamente para potenciar las capacidades que posibiliten responder, de manera digna, a los desafíos que tal exclusión implica. Dichos desafíos y dichas respuestas serán diferentes, como distintas las configuraciones (y las contradicciones) geográficas e históricas en cada territorio que esos actores sociales habiten.

\section{Recomendaciones para la definición de políticas.}

El "acompañamiento" de la universidad a las comunidades que se encuentran en territorios, en espacios que se significan y resignifican-mediante decisiones que desarrollan actores determinados, que buscan solucionar problemas relevantes-, amerita formular, desarrollar y evaluar procesos de extensión planificados y continuos con las comunidades, para lo cual se requiere profundizar en las definiciones de regionalización y desconcentración, planteadas en los fines ${ }^{12}$ y acciones ${ }^{13}$ de la UNA. Estas acciones deben abordar

12 Estatuto Orgánico aprobado por la Asamblea Universitaria mediante referéndum realizado el 31 de octubre de 2014. CAPÍTULO ÚNICO: PRINCIPIOS, VALORES Y FINES. c. Regionalización. La Universidad Nacional aporta al desarrollo del país mediante la ampliación, diversificación y mejoramiento de su acción sustantiva, como respuesta a las necesidades y demandas de regiones específicas. d. Desconcentración. Es una forma de organización mediante la cual se le otorga a un órgano o instancia determinadas facultades de decisión y ejecución autónoma de su presupuesto, para que su gestión se desarrolle de forma ágil y eficiente.

13 "Según el informe de la Vicerrectoría de extensión, en el período 2011-2015 se ejecutaron alrededor de 180 proyectos integrados de extensión por año en diversas temáticas como son: salud y calidad de vida ( $25 \%$ del total); ambiente y conservación (13\%); producción alimentaria (13\%), sociedad y desarrollo humano (13\%), entre otros 10.Con estos PPAA se fortalecen y desarrollan capacidades para la investigación y la extensión en académicos, que a su vez contribuyen a la mejora de la calidad y la pertinencia de los PPAA". 
un enfoque de territorialidad que desemboque en el autodesarrollo o en el desarrollo autogestado por las personas de las comunidades, en beneficio del fortalecimiento local, que les permita beneficiarse en interacción con los sujetos de la entidad universitaria.

La extensión universitaria debe decidiren relación con estos fines institucionales,

- El estudio continuo, sistemático y participativo de los procesos de desarrollo en las regiones y territorios más desiguales del país, ${ }^{14}$ con el fin de identificar condiciones y oportunidades, necesidades de apoyo y coordinación intrainsitucional (intersedes, sedes, secciones y estaciones) e interinstitucional (universidades públicas, entidades gubernamentales u otras de interés, ubicadas en cada región y territorio), desde las diferentes unidades académicas, mediante instancias articuladoras, creadas para tal fin (espacios con instrumentos de verificación en todo el ciclo de la planificación-diseño, ejecución, seguimiento y control, evaluación en todos los niveles gerenciales: políticas, planes, programas y proyectos).

- Construir desde una extensión crítica ${ }^{15}$ y el diálogo de saberes, con la creación de modelos y unidades de coordinación regional debidamente institucionalizadas, que promuevan el desarrollo participativo, sustentable y que generen equidad territorial, mediante procesos de capacitación, investigación y docencia dirigidos al desarrollo comunitario participativo.

- Promover la equidad territorial mediante las alianzas estratégicas con actores locales públicos y privados, congruentes con los valores y fines universitarios, con quienes articular propuestas sustentables de desarrollo glocal para las comunidades, basados en estudios de las realidades comunitarias (hechos con participación comunitaria).

14 Entiéndase de forma prioritaria las comunidades con mayor índice de pobreza, ubicadas en zonas fronterizas y costeras.

15 Tommasino y Cano hablan de "extensión crítica" para referirse a la concepción extensionista heredera de la pedagogía freiriana. Boaventura de Sousa Santos, por su parte, ha formulado la idea de una "ecología de saberes" en cuya búsqueda se combine a la extensión con lo que llama una "extensión en sentido contrario" (Tommasino y Cano, 2006, p. 38), consistente en la incorporación sistemática de la agenda, prioridades y saberes de los movimientos sociales al interior de la universidad. Idea similar a la planteada por Diego Tatián cuando habla de "intensión universitaria" en el marco de su propuesta de "autonomía heterogénea" y "universidad común" (Tatián, 2013, citado por Tommasino y Cano, 2006, p. 6). 
ReVista Universidad en DiÁlogo • Vol. 8, N. ํㄹ 2, Julio-Diciembre, 2018, pp. 51-69

ISSN 2215-2849 • EISSN: 2215-4752

DOI: http://dx.doi.org/10.15359/udre.8-2.4

- Promover en los procesos educativos universitarios sobre extensión el reconocimiento a la diversidad local y a la interculturalidad en los procesos de desarrollo territorial.

- Promover el intercambio reflexivo de experiencias entre equipos de extensión (incluye estudiantes) a nivel de sedes, subsedes, intersedes y otras, que fortalezcan los procesos de enseñanzaaprendizaje de la extensión.

- Incluir los ejes transversales de gestión del riesgo y cambio climático, enfoque de género y enfoque de derechos en todas las acciones de extensión.

- Abordar la extensión en comunidades a partir de enfoques multidimensionales (social, económica, ambiental y tecnológicamente, ${ }^{16}$ y políticamente integrados), interdisciplinarios y transdisciplinarios, en estrecha vinculación con la investigación y la docencia.

- Desarrollar una extensión mediante "Consejos de vinculación regional interconectados", ${ }^{17}$ que reciban sustento continuo y planificado de los "observatorios de desarrollo regional", donde quiera que se necesite monitorear los avances del desarrollo glocal, cuyas acciones permitan incidir en la gestación, gestión, ejecución y evaluación de la política pública para la equidad en territorios.

- Fortalecer el intercambio internacional con redes, instituciones y universidades que promueven la extensión desde concepciones equitativas y con un amplio compromiso social con los sectores menos favorecidos.

\section{Referencias}

Arias, R. y Sánchez, L. (2013). Decimoctavo Informe del Estado de la Nación en Desarrollo Humano Sostenible. Informe final: Análisis de la desigualdad socioeconómica en Costa Rica por criterio

\footnotetext{
16 Tecnológicamente integrados se refiere al uso de las tecnologías de la comunicación y la información (TIC) para acortar distancias y abaratar costos entre regiones, para aumentar el impacto en los ciclos de intervención para el desarrollo en comunidades, desde la extensión.

17 Propuesta basada en el documento de Alvarado (2014). Regionalización, el gran desafio. Sin publicar.
} 
territorial. Recuperado de https://estadonacion.or.cr/files/biblioteca virtual/018/arias y sanchez desigualdad socioeconomica criterio_territorial.p.pd

Alvarado, H. (2014). Regionalización, el gran desafio. Sin publicar.

Barrantes, F. (1997). La regionalización del sistema educativo costarricense mito y realidad. Ministerio de Educación Pública. Coloquio Regional sobre Descentralización de la Educación en América Central, Cuba y República Dominicana. Recuperado de http://unpan1.un.org/ intradoc/groups/public/documents/clad/clad0031503.pdf

Castro, G. S. (2007). Decolonizar la universidad. La hybris del punto cero y el diálogo de saberes. Recuperado de http://www.ram-wan.net/restrepo/ decolonial/14-castro-descolonizar\%201a\%20universidad.pdf

Carmen, R. (2004). Desarrollo Autónomo. Humanización del paisaje: una incursión en el pensamiento y la práctica radical. Heredia, Costa Rica: Editorial Universidad Nacional.

De Sousa, B. (2007). La universidad en el siglo XXI. Para una reforma democrática y emancipatoria de la universidad. La Paz: CIDES-UMSA.a/index_es.htm

Eurosocial (2017). Experiencia destacada. Política de Estado para el desarrollo regional: reduciendo brechas sociales en Costa Rica. Diálogo para la acción, 50-51. Recuperado de http://www.sia. eurosocial-ii.eu/files/docs/ficha_experiencia_politicasestado_ costarica.pdf

Fürst, E. (2013). Crisis, espacio y aprendizaje social: la cuestión regional en el capitalismo global. Heredia, Costa Rica: EUNA.

González,C.(2017).¿Aquiénpertenecenlospueblos? Recuperadodehttps:/www. facebook.com/cristhian.o.gonzalezgomez?hc_ref=NEWSFEED\&frefnf

Hernández, G. (2017). El territorio costarricense, un imaginario social en crisis. Heredia: PDCS-UNA.

León, A. (2015). Desarrollo geográfico desigual en Costa Rica: el ajuste estructural visto desde la Región Huetar Norte (1985-2005). San José: Editorial Universidad de Costa Rica. 
ReVista Universidad en Diálogo • Vol. 8, N. ${ }^{\circ}$ 2, Julio-Diciembre, 2018, pp. 51-69

ISSN 2215-2849 • EISSN: 2215-4752

DOI: http://dx.doi.org/10.15359/udre.8-2.4

Miranda, R. (2010). La noción de alteridad en Cornelius Castoriadis. Tesis doctoral. Universidad Complutense de Madrid. Recuperado de http://eprints.ucm.es/11034/1/T32189.pdf

Programa Estado de la Nación en Desarrollo Humano Sostenible (2000). Capitulo 3. La estabilidad democrática en la Costa Rica contemporánea. Recuperado de https://issuu.com/estadonacion/ docs/aud_cal_dcap3

Programa Estado de la Nación en Desarrollo Humano Sostenible (2016). Vigésimo Segundo Informe del Programa Estado de la Nación. San José, Costa Rica: PEN CONARE. Recuperado de http://www. estadonacion.or.cr/22/

Programa Estado de la Nación (2017). Sexto Informe del Estado de la Educación. San José, Costa Rica: CONARE. Recuperado de http:// www.estadonacion.or.cr/educacion2017/assets/parte-1-capitulo-5.pdf

Robinson, W. (2015). América Latina y el capitalismo global. Una perspectiva crítica de la globalización. México: Siglo XXI Editores.

Sosa, M. (2012). ¿Cómo entender el territorio? Guatemala: Editorial Cara Parens. Recuperado de http://www.rebelion.org/docs/166508.pdf

Samper, M., \& Torrens, J. (s. f.). Políticas públicas para el desarrollo de los territorios rurales. Recuperado de http://cdr.or.cr/libro/Cap1.pdf

Sotolongo, P., \& Delgado, C. (2006). La revolución contemporánea del saber y la complejidad social: hacia unas ciencias sociales de nuevo tipo. Buenos Aires: Consejo Latinoamericano de Ciencias Sociales CLACSO. Recuperado de http://www.paginaspersonales.unam.mx/ files/266/sotolongo.pdf

Tommasino, H., \& Cano, A. (enero-marzo, 2016). Modelos de extensión universitaria en las universidades latinoamericanas en el siglo XXI: tendencias y controversias. Revista Universidades, 67, 7-24. Recuperado de https://www.researchgate.net/ publication/293952059_Modelos_de_extension_universitaria en_las_universidades_latinoamericanas_en_el_siglo_XXI_ tendencias_y_controversias 
Universidad Nacional (2015). Reglamento de reformas del Estatuto Orgánico de la Universidad Nacional. Alcance No.1 a la UNAGaceta 7-2016. Recuperado de http://www.documentos.una.ac.cr/ bitstream/handle/unadocs/6693/ESTATUTO-ORG\%C3\%81NICOUNA-digital.pdf?sequence $=1 \&$ isAllowed $=\mathrm{y}$

Wallerstein, I. (1999). Impensar las ciencias sociales. Límites de los paradigmas decimonónicos. México: Editorial Siglo XXI.

Zlaveta, P. (2016). La universidad necesaria: análisis de proyectos de extensión de la Universidad Nacional de Costa Rica desde el enfoque de desarrollo humano y capacidades. Tesis de Maestría. Universidad de Valencia, España. 